\title{
Work-related musculoskeletal disorders among dental professionals in Saudi Arabia
}

\author{
Ahmad Alghadir, PT, PhD ${ }^{1)}$, Hamayun Zafar, PT, PhD ${ }^{1,2)}$, Zaheen A. IQbal, PT, MPT ${ }^{1)^{*}}$ \\ 1) Rehabilitation Research Chair, Department of Rehabilitation Sciences, College of Applied Medical \\ Sciences, King Saud University: Riyadh 11433, Saudi Arabia \\ 2) Department of Odontology, Clinical Oral Physiology, Umea University, Sweden
}

\begin{abstract}
Purpose] Musculoskeletal disorders are common causes of work-related disability in different professions involving the frequent practice of lifting, stooping, twisting, prolonged sitting, or standing. The dental profession is one such profession. Our aim was to determine the prevalence of work-related musculoskeletal disorders among dental professionals in Saudi Arabia, the factors associated with them, and their consequences and to propose preventive measures for them. [Subjects and Methods] A self-administered online questionnaire was sent to 225 members of the Saudi Dental Association. It included questions on demographic and professional characteristics, general medical history, and history of work-related musculoskeletal disorders before and after joining the dental profession. [Results] The questionnaire was completed by $65 \%$ of the respondents. Among them $85 \%$ reported that they had developed some pain due to work after joining the dental profession, and $42 \%$ reported that they were suffering pain at the time of the survey. Besides lower back, shoulder, and neck regions, the hands, upper back, and other regions like the elbows, buttocks, thighs, leg, and feet were areas in which they pain. [Conclusion] The prevalence of work-related musculoskeletal disorders among dental professionals in Saudi Arabia is high, affecting their daily activities, sometimes even forcing them to change their work setting. Age, gender, specialty of work, work setting, number of contact hours with patients, etc., were all found to be related to their work-related pain. We need to emphasize the role of ergonomics, counseling, proper techniques of patient handling, etc., during the training of dental professionals so that they can work efficiently.

Key words: Work-related musculoskeletal disorders, Dentists, Saudi Arabia
\end{abstract}

(This article was submitted Sep. 25, 2014, and was accepted Dec. 11, 2014)

\section{INTRODUCTION}

Musculoskeletal disorders are a common cause of workrelated disability in different professions ${ }^{1)}$. The physical aspect of work associated with such professions has been identified as a risk factor for developing work-related musculoskeletal disorders (WRMDs). In dentistry, overstrained and awkward postures, repetitiveness of different joint movements, use of high frequency vibration tools, and psychological stress have been identified as risk factors ${ }^{2,3)}$.

In the last decade, various studies have been published around the world citing the high prevalence of WRMDs among dental professionals ${ }^{2-5}$. The most affected regions reported are the back and neck ${ }^{5}$ ). The need for prevention of these disorders has been identified, including identification and modification of risk factors associated with this profes$\operatorname{sion}^{4}$.

The data on the prevalence of WRMDs for different

\footnotetext{
*Corresponding author. Zaheen A. Iqbal (E-mail:
} z_iqbal001@yahoo.com)

(C2015 The Society of Physical Therapy Science. Published by IPEC Inc. This is an open-access article distributed under the terms of the Creative Commons Attribution Non-Commercial No Derivatives (by-ncnd) License $<$ http://creativecommons.org/licenses/by-nc-nd/3.0/> . professions can provide the basis for formulation of necessary strategies to prevent them in the future. However, to our knowledge, no data on the incidence or prevalence of WRMD among dental professionals has been reported previously in Saudi Arabia.

The objectives of this study were to report the prevalence of WRMDs among dental professionals working in Saudi Arabia; identify factors, such as age, gender, subspecialties of dentistry, and the work environment, that might be associated with them; determine how WRMDs affect their work and activities of daily living; and propose some preventive measures.

\section{SUBJECTS AND METHODS}

The questionnaire used to collect data for this study was based on similar studies published previously $\left.{ }^{2}, 3,5,6\right)$ and was adapted to the Saudi work culture for use among dental professionals working in Saudi Arabia. The study fully complied with the ethical standards for human research of King Saud University.

The questionnaire included 43 questions pertaining to three domains, demographic and professional characteristics, general medical history, and history of WRMD before and after joining the dental profession. These domains included questions pertaining to work setting characteristics and the 
Table 1. Demographic data

\begin{tabular}{|c|c|c|c|}
\hline & Females & Males & Total \\
\hline \multicolumn{4}{|c|}{ Total respondents } \\
\hline AGE & $69(47)$ & $77(52)$ & $146(100)$ \\
\hline$<40$ & $46(45)$ & $56(55)$ & $102(70)$ \\
\hline $40-50$ & $21(66)$ & $11(34)$ & $32(22)$ \\
\hline$>50$ & $02(17)$ & $10(83)$ & $12(8)$ \\
\hline \multicolumn{4}{|c|}{ Height $(\mathrm{cm})$} \\
\hline$<168$ & $51(82)$ & $11(18)$ & $62(42)$ \\
\hline $168-177$ & $17(29)$ & $41(71)$ & $58(40)$ \\
\hline$>177$ & $01(04)$ & $25(96)$ & $26(17)$ \\
\hline \multicolumn{4}{|c|}{ Weight (kg) } \\
\hline$<60$ & $30(81)$ & $07(19)$ & $37(25)$ \\
\hline $60-80$ & $34(50)$ & $34(50)$ & $68(47)$ \\
\hline$>80$ & $05(12)$ & $36(88)$ & $41(28)$ \\
\hline \multicolumn{4}{|c|}{ Work experience (years) } \\
\hline$<2$ & $08(42)$ & $11(58)$ & $19(13)$ \\
\hline $2-5$ & $18(78)$ & $15(22)$ & $33(23)$ \\
\hline$>5$ & $43(46)$ & $51(54)$ & $94(64)$ \\
\hline \multicolumn{4}{|c|}{ Direct patient contact (hours/week) } \\
\hline$<25$ & $19(44)$ & $24(56)$ & $43(29)$ \\
\hline $25-30$ & $25(55)$ & $20(45)$ & $45(31)$ \\
\hline$>30$ & $25(43)$ & $33(57)$ & $58(40)$ \\
\hline
\end{tabular}

Values in the tables are numbers followed by percentages in parentheses

effect of WMRD on dentists' daily work and non-work activities. WRMD was defined as any unpleasant sensation in the musculoskeletal system of the body developed after joining the dentistry profession.

The questionnaire was uploaded online, and the web link for the survey along with an explanation of the purpose of the study were sent to 225 members of the Saudi Dental Association (SDA) working in Saudi Arabia, inviting them to participate in the study. Respondents were assured of confidentiality of their information. Two weeks after uploading the questionnaire online, a reminder email was also sent.

Dental professionals who were members of the SDA and involved in direct patient contact for at least 10 hours per week were eligible to participate. The participants had to complete the questionnaire online. Incomplete questionnaires were rejected.

\section{RESULTS}

Out of $225,146(65 \%)$ members of the SDA completed the online questionnaire. Among them, 69 (47\%) were females, and $77(52 \%)$ were males. The majority of the respondents, $102(70 \%)$, were under the age of 40 years (Table 1). Overall, $94(64 \%)$ of the respondents were Saudi in origin. However, no difference in prevalence of WRMDs based on nationality was observed. Out of the 146 respondents, $119(81 \%)$ respondents indicated that they were satisfied with their job.

Of the 146 respondents, 134 (92\%) were dentists, 6 (4\%) were dental assistants, $5(3 \%)$ were dental hygienists, and $1(1 \%)$ was a dental technician. Among the respondents 68 (47\%) had only a Bachelor's degree, while 35 (24\%) and
Table 2. Basic data and WRMD characteristics before joining dental profession

\begin{tabular}{lccc}
\hline & Females & Males & Total \\
\hline Speciality & & & \\
Orthodontics & $13(48)$ & $10(08)$ & $23(16)$ \\
Endodontics & $21(27)$ & $25(35)$ & $46(31)$ \\
Prosthodontics & $14(02)$ & $17(08)$ & $31(21)$ \\
Periodontics & $09(22)$ & $14(01)$ & $23(16)$ \\
Pediatrics & $12(22)$ & $11(01)$ & $23(16)$ \\
Work setting & & & \\
Hospital & $25(51)$ & $244(49)$ & $49(34)$ \\
Clinic & $24(60)$ & $16(40)$ & $40(27)$ \\
University & $13(31)$ & $29(69)$ & $42(29)$ \\
Private & $03(33)$ & $06(67)$ & $09(06)$ \\
Community care & $04(67)$ & $02(33)$ & $06(04)$
\end{tabular}

Physical disability or functional limitations before joining dental profession

$$
\begin{array}{lllr}
\text { Yes } & 04(36) & 07(64) & 11(05) \\
\text { No } & 65(48) & 70(52) & 135(93)
\end{array}
$$

WRMDs before joining dental profession

\begin{tabular}{lllr} 
Yes & $12(60)$ & $08(40)$ & $20(14)$ \\
No & $61(48)$ & $65(52)$ & $126(86)$ \\
\hline
\end{tabular}

Values in the tables are numbers followed by percentages in parentheses

$30(20 \%)$ also had a Master's degree and $\mathrm{PhD}$ degrees, respectively. the remaining $13(9 \%)$ had a diploma certificate. Ninety-four (64\%) had work experience (WE) of more than 5 years. Most of the respondents, 138 (94\%), reported that they worked as a full time professionals with patient contact of more than 15 hours per week (Table 1).

The majority of the respondents, 46 (31\%) had endodontics as their area of specialty. Thirty-seven (94\%) respondents were employed in the government sector, while $9(6 \%)$ were employed in the private sector. The main employers were hospitals, with 49 (34\%) respondents employed in the (Table 2).

One hundred and thirteen respondents (80\%) reported that they were not under treatment for any medical condition. Among the rest, 19 (57\%) reported that they had hypertension, $14(43 \%)$ reported that they had diabetes, and 2 (7\%) reported that they had cardiac disease. Fifty-five (39\%) respondents reported that they had complaints of headache at least three times a week, forcing $26(18 \%)$ of them to seek treatment.

The most common position adopted during daily work routine was sitting, with $116(79 \%)$ respondents reporting that they sat, while $30(20 \%)$ reported that they stood. Among those who reported sitting 70 (56\%) respondents reported that they used a revolving chair in their set up, and only $20(16 \%)$ used chairs with an arm rest.

Out of the 146 respondents, $126(86 \%)$, constituting 61 females and 65 males, reported that they had no musculoskeletal pain disorder, and 135 (93\%) reported no functional limitation or physical disability before joining the dental 
Table 3. Distribution of WRMDs among respondents after joining dental profession (most of the respondents had complaints in multiple locations)

\begin{tabular}{lccc}
\hline Location & Females & Males & Total \\
\hline Neck & $33(56)$ & $26(44)$ & $59(48)$ \\
Shoulder & $34(58)$ & $25(42)$ & $59(48)$ \\
Elbow & $02(67)$ & $01(33)$ & $03(2)$ \\
Hand & $20(59)$ & $14(41)$ & $34(27)$ \\
Upper back & $15(52)$ & $14(48)$ & $29(23)$ \\
Lower back & $32(43)$ & $42(57)$ & $74(60)$ \\
Low back and buttocks & $04(44)$ & $05(56)$ & $09(07)$ \\
Thighs and knee & $04(66)$ & $05(34)$ & $06(05)$ \\
Lower leg & $06(75)$ & $02(25)$ & $08(06)$ \\
Foot & $12(70)$ & $05(30)$ & $17(14)$ \\
Others & $02(50)$ & $02(50)$ & $04(03)$ \\
\hline
\end{tabular}

Values in the tables are numbers followed by percentages in parentheses

profession (Table 2). On the other hand 124 (85\%) reported that they had developed some sort of musculoskeletal pain after joining the dental profession. Among these respondents, $37(30 \%)$ reported that their pain was sudden in origin, and the average duration of pain was greater than 4 weeks in 19 (16\%) respondents. At least $52(42 \%)$ respondents reported that they were suffering from work-related pain at the time of the survey (Table 4). However, only 47 (38\%) respondents suffering from musculoskeletal pain due to work reported that they sought some treatment for their condition.

On a Visual Analog Scale (VAS) ranging from 0 to 10, $13(10 \%)$ of the respondents reported their worst ever pain as less than 3, $30(24 \%)$ reported it between 3 and 5, while in $81(65 \%)$ reported it was more than 5 . Out of these 81 respondents, $15(12 \%)$ respondents reported their worst pain as 10 out of 10 . The distribution of WRMDs is given in Table 3. Most of the respondents had work-related pain in more than one region. Among 124 respondents reporting that they suffered from WRMDs, most of the respondents, $74(60 \%)$ reported pain in the lower back region.

Fifty-one (41\%) of respondents who reported development of WRMDs after joining the dental profession reported that they were unable to practice their regular daily activities involving bending, twisting, stooping, etc. Forty-seven $(38 \%)$ respondents reported that they had to decrease their non-work-related activities due to pain, while 48 (39\%) reported that they were unable to practice their daily work activities. Patient handling/treatment was reported to be the most difficult task by $33(27 \%)$ respondents. The severity of WRMDs forced 49 (39\%) respondents to go on sick leave, and $9(7 \%)$ of the respondents reported that they had claimed compensation due to their WMRDs (Table 4).

Respondents attributed their pain to various different reasons. Out of 124 respondents, 90 (73\%) reported that their WRMDs were due to frequent strenuous back positions during work, $71(57 \%)$ reported that they were due to repetitive shoulder/hand movements, 51 (41\%) reported that they were due to high job demand, and $10(8 \%)$ reported use of vibrating tools as the cause of their pain. Another $38(30 \%)$ reported other causes like high exertion and low job control as the reason for their WRMDs.

Out of 124 respondents with WRMDs, 47 (39\%) sought treatment for their pain, while the remaining 77 (62\%) did not seek any treatment. Physical therapy was sought by at least $15(32 \%)$ respondents, while the remaining respondents reported either consultation of a physician or taking muscle relaxants and analgesics for their pain.

Among the $102(70 \%)$ respondents who were under 40 years of age, 37 (36\%) reported suffering from WRMDs at the time of the survey. Compared with older respondents, who had the most complaints in the back and neck, these young respondents complained more about pain in other parts of the body like shoulders, knees, feet and hands. Respondents with WE of more than 5 years reported a higher prevalence of WRMDs than those with lesser WE.

Out of the 124 respondents who suffered from WRMDs after joining the dental profession, 61 were females and 63 were males. This accounts for $88 \%$ and $82 \%$ of all female and male respondents. Compared with males, the duration of pain in females was longer. The majority of males have the most pain complaints in the lower back, neck, and shoulder regions. However, females reported experiencing pain in these regions in addition to the hand and knee regions (Tables 3 and 4).

Specialists in pediatrics, accounting for 21 respondents (91\%), were the most affected aby WRMDS, followed by endodontics accounting for 41 (89\%) respondents. Twentysix $(84 \%)$ prosthodontists reported to develop work-related pain, while $18(78 \%)$ orthodontists and periodontists reported development of WRMDs after joining their professions.

Respondents with more patient contact had higher prevalence of WRMDs. Among those with patient contact of more than 30 hours per week, 27 (59\%) reported severe pain in one or more region. Compared with those with less patient contact, the location of pain in respondents with patient contact of more 30 hours per week was widely distributed, forcing at least $20(34 \%)$ of them to go on sick leave.

The location of the pain among the respondents seemed to be related to the type of chairs they used in their clinical facilities. Respondents who used a revolving chair had a higher prevalence of WRMDs, with 32 (54\%) of them complaining of pain in the neck region and $36(61 \%)$ complaining of pain in the shoulder region. Respondents using chairs with arm rests had less pain complaints than those reporting using chairs without arm rests, with 38 (51\%) complaining of pain in the lower back and 34 (58\%) each complaining of pain in the neck and shoulder region (Table 5).

\section{DISCUSSION}

The prevalence of WRMDs among dental professionals in Saudi Arabia was found to be high, with at least $85 \%$ of the respondents reporting development of some musculoskeletal pain after joining the dental profession. Out of these respondents, $52 \%$ reported that they were suffering from pain at the time of the survey. Our data suggests that age, gender, duration of contact with patients per week, the chairs used in the clinics, and area of dental specialty are all related to this high prevalence. This is first study of its kind to be 
Table 4. WRMD characteristic after joining dental profession

\begin{tabular}{|c|c|c|c|}
\hline & Females & Males & Total \\
\hline \multicolumn{4}{|l|}{ Current pain } \\
\hline Yes & $30(42)$ & $42(58)$ & $72(58)$ \\
\hline No & $31(60)$ & $21(40)$ & $52(42)$ \\
\hline \multicolumn{4}{|l|}{ Onset of pain } \\
\hline Sudden & $16(10)$ & $21(29)$ & $37(30)$ \\
\hline Gradual & $45(20)$ & $42(18)$ & $87(70)$ \\
\hline \multicolumn{4}{|l|}{ Average duration of pain } \\
\hline$<2$ weeks & $35(44)$ & $45(56)$ & $80(64)$ \\
\hline $2-4$ weeks & $16(64)$ & $09(36)$ & $25(20)$ \\
\hline$>4$ weeks & $10(53)$ & $10(47)$ & $19(16)$ \\
\hline \multicolumn{4}{|c|}{ Effect of pain on daily activities } \\
\hline No & $31(42)$ & $42(58)$ & $73(59)$ \\
\hline Yes & $30(59)$ & $21(41)$ & $51(41)$ \\
\hline \multicolumn{4}{|l|}{ Activities limited due to pain } \\
\hline Bending & $15(47)$ & $17(53)$ & $32(26)$ \\
\hline Twisting & $22(51)$ & $21(49)$ & $43(35)$ \\
\hline Stooping & $00(00)$ & $03(100)$ & $03(02)$ \\
\hline Patient handling/ Treatment & $18(55)$ & $15(45)$ & $33(27)$ \\
\hline Prolonged sitting & $17(41)$ & $24(59)$ & $41(33)$ \\
\hline Prolonged standing & $14(87)$ & $16(13)$ & $30(24)$ \\
\hline Others & $06(50)$ & $06(50)$ & $12(10)$ \\
\hline \multicolumn{4}{|c|}{ Effect of pain on work activities } \\
\hline No & $26(54)$ & $22(46)$ & $48(39)$ \\
\hline Yes & $35(58)$ & $41(42)$ & $76(61)$ \\
\hline \multicolumn{4}{|l|}{ Outcome of WRMDs } \\
\hline Sick leave & $29(59)$ & $20(41)$ & $49(39)$ \\
\hline Compensation & $05(55)$ & $04(45)$ & $09(07)$ \\
\hline Reduced non work activities & $14(52)$ & $13(48)$ & $27(22)$ \\
\hline Reduced working hours & $15(52)$ & $14(48)$ & $29(23)$ \\
\hline Change of work setting & $16(34)$ & $31(66)$ & $47(38)$ \\
\hline Others & $08(53)$ & $07(47)$ & $15(12)$ \\
\hline
\end{tabular}

Values in the tables are numbers followed by percentages in parentheses done in Saudi Arabia.

Our findings are the same as those of previous similar studies done around the world, such as in Greece ${ }^{6)}$, Sweden $^{3,8)}$ and $\mathrm{Canada}^{7)}$, reporting dentistry to be a high risk profession for development of WRMDs. In most of these studies, back pain was the most reported WRMD among dentists, with its prevalence ranging from $37 \%$ and $55 \%{ }^{2,9-11)}$. In our study, along with pain in the lower back region (reported by $60 \%$ of the respondents), pain in the neck and shoulder regions (48\% each), hands $(27 \%)$, upper back region $(23 \%)$, and in other regions like the elbows, buttocks, thighs, leg, foot, etc. $(26 \%)$, also showed a high prevalence.

The respondents in our study were relatively younger, with $70 \%$ of them under 40 years of age. Among these respondents, at least $36 \%$ had work experience of less than 5 years (Table 1). The high prevalence of work-related pain in these young professionals is either due to overload in the work setting, faulty ergonomics, or incorrect techniques used during treatment of patients ${ }^{12,13)}$. Such professionals are at the beginning of their career. As WRMDs are known to increase with age, if dental professionals suffer pain at this point in their lives, the problem could grow, making it difficult for them to practice in the future. Strategies need to be developed that can help them to continue clinical practice without such problems ${ }^{14)}$.

Our study is in line with the previous studies showing WRMDs to be gender related ${ }^{15}$. The prevalence of WRMDs after joining the dental profession was found to be high in female professionals compared with their male counterparts. This is accounted for by their higher body weight, smaller height, and differences in muscle strength and composition ${ }^{16-18)}$. Smaller body builds among females (Table 1) acts as a disadvantage when lifting or transferring equipment and when applying body force during treatment, putting an extra load on their bodies especially the spine.

Furthermore, in our study, specialists from pediatrics seemed to be at the most risk of developing WRMDs with $91 \%$ of them reporting some work-related pain. However, the distribution of pain is different in specialists from different areas of dentistry. In orthodontists, $27 \%$ each specialists

Table 5. Chairs used in clinic and location of pain

\begin{tabular}{|c|c|c|c|c|c|}
\hline Location of pain & Total & Fixed chair & Revolving chair & $\begin{array}{c}\text { Chair with } \\
\text { armrests }\end{array}$ & $\begin{array}{c}\text { Chair without } \\
\text { armrests }\end{array}$ \\
\hline Neck & $59(48)$ & $02(03)$ & $32(54)$ & 07 (12) & $34(58)$ \\
\hline Shoulder & $59(48)$ & $01(02)$ & $36(61)$ & $03(05)$ & $34(58)$ \\
\hline Elbow & $03(02)$ & $00(00)$ & $01(33)$ & $00(00)$ & $03(66)$ \\
\hline Hand & $34(27)$ & $02(06)$ & $20(58)$ & $04(12)$ & $17(50)$ \\
\hline Upper back & $29(23)$ & $00(00)$ & $19(66)$ & $03(10)$ & $11(38)$ \\
\hline Lower back & $74(60)$ & $01(01)$ & $43(58)$ & $13(18)$ & $38(51)$ \\
\hline Lower back and buttocks & $09(07)$ & $00(00)$ & $04(44)$ & $02(22)$ & $04(44)$ \\
\hline Thighs & $06(05)$ & $00(00)$ & $03(50)$ & $02(33)$ & $03(50)$ \\
\hline Lower leg & $08(06)$ & $00(00)$ & $02(25)$ & $03(37)$ & $03(37)$ \\
\hline Foot & $17(14)$ & $00(00)$ & $08(47)$ & $03(18)$ & $07(41)$ \\
\hline
\end{tabular}

Values in the tables are numbers followed by percentages in parentheses 
reported pain either in the neck or lower back region. In endodontists, the elbow region (20\%) was reported to be a major area of pain. In prosthodontists and periodontists, pain in the hand (20\% each) was the most reported WRMD. In respondents with pediatric specialists, knee pain (22\%) was the major reported WRMD. Such differences in the prevalence of various WRMDs among dentists from different specialties have been observed in previous studies ${ }^{6,19)}$ and can be accounted for by the difference in nature of the duties they perform and whether they have direct patient contact or not. Work posture during the scaling procedure has been reported as a risk factor for development of WRMDs ${ }^{20}$.

Work-related disorders seem to have a major effect on their daily activities other than work, especially in those with patient contact of more than 30 hours in a week. Respondents reported significant decrease in activities like shopping, cooking, and other home duties. At least $40 \%$ of them reported that they had to go on sick leave, $23 \%$ had to reduce their working hours, and $39 \%$ had to seek some treatment for their pain. Other studies have also reported sickness absence, changing the work setting, and even claiming compensation as the outcome of WRMDs ${ }^{6,21)}$. Respondents felt unhappy and "low" after their work time and reported that this affected their care of patients. They should be encouraged to discuss their workloads, self-efficacy and personal health ${ }^{14)}$.

In previous studies a significant relation has been found between self-reported risk factors and the occurrence of WRMDs in different parts of the body ${ }^{6}$. Similarly, in our study, risk factors reported include frequent strenuous back position during work, repetitive shoulder/hand movements, use of vibrating tools, use of revolving chairs hairs and chairs without armrests, high job demand, and others like high exertion and low job control. Height adjustable chairs with armrests/supports have been ergonomically proven to be an efficient intervention for reducing musculoskeletal pain $^{22,23)}$. Both physical load and psychological factors play an important role in maintaining general health.

Beyond a limit, patient handling/treatment has also been known to cause WRMDs among other health professionals like physical therapists ${ }^{17,21)}$, nurses ${ }^{24-26)}$, and other care givers ${ }^{27)}$. Preventive measures should always be considered while handling the patients by incorporating special equipment, suspension frames, automatic chairs, and height adjustable beds. The role of ergonomics, proper techniques of carrying and lifting, healthy work environment, team work, prevention of injury, counseling, etc., needs to be emphasized during training of health professionals so that they can use their body force efficiently and effectively without putting an extra load on any specific part of the body. Ergonomics may be introduced as a separate course during their studies.

The prevalence of work-related musculoskeletal disorders among dental professionals in Saudi Arabia is high, affecting their daily activities, sometimes even forcing them to change their work setting. Age, gender, specialty of work, work setting, number of contact hours with patients, etc. were all found to be related to their work-related pain. We need to emphasize the role of ergonomics, counseling, proper techniques of patient handling, etc., during the training of dental professionals so that they can work efficiently.

This study needs to be repeated with a long-term follow- up to see how such professionals cope with such a challenge. We need to devise primary as well as secondary prevention strategies to decrease the prevalence of WRMDs among dental professionals so that can effectively take care of patient and focus on their work.

This study used a self-report questionnaire to be completed by the respondents, who described their own conditions. There is a possibility that they may have overestimated their past experiences. Dental professional who were not members of SDA were not included in the study.

\section{ACKNOWLEDGEMENT}

This project was financially supported by King Saud University, Vice Deanship of Research Chairs, Rehabilitation Research Chair.

\section{REFERENCES}

1) Andersson GB: Epidemiological features of chronic low-back pain. Lancet, 1999, 354: 581-585. [Medline] [CrossRef]

2) Szymańska J: Disorders of the musculoskeletal system among dentists from the aspect of ergonomics and prophylaxis. Ann Agric Environ Med, 2002, 9: 169-173. [Medline]

3) Akesson I, Lundborg G, Horstmann V, et al.: Neuropathy in female dental personnel exposed to high frequency vibrations. Occup Environ Med, 1995, 52: 116-123. [Medline] [CrossRef]

4) Sharma P, Golchha V: Awareness among Indian dentist regarding the role of physical activity in prevention of work related musculoskeletal disorders. Indian J Dent Res, 2011, 22: 381-384. [Medline] [CrossRef]

5) Hayes M, Cockrell D, Smith DR: A systematic review of musculoskeletal disorders among dental professionals. Int J Dent Hyg, 2009, 7: 159-165. [Medline] [CrossRef]

6) Alexopoulos EC, Stathi IC, Charizani F: Prevalence of musculoskeletal disorders in dentists. BMC Musculoskelet Disord, 2004, 5: 16. [Medline] [CrossRef]

7) Liss GM, Jesin E, Kusiak RA, et al.: Musculoskeletal problems among Ontario dental hygienists. Am J Ind Med, 1995, 28: 521-540. [Medline] [CrossRef]

8) Oberg T, Oberg U: Musculoskeletal complaints in dental hygiene: a survey study from a Swedish county. J Dent Hyg, 1993, 67: 257-261. [Medline]

9) Ratzon NZ, Yaros T, Mizlik A, et al.: Musculoskeletal symptoms among dentists in relation to work posture. Work, 2000, 15: 153-158. [Medline]

10) Finsen L, Christensen H, Bakke M: Musculoskeletal disorders among dentists and variation in dental work. Appl Ergon, 1998, 29: 119-125. [Medline] [CrossRef]

11) Lehto TU, Helenius HY, Alaranta HT: Musculoskeletal symptoms of dentists assessed by a multidisciplinary approach. Community Dent Oral Epidemiol, 1991, 19: 38-44. [Medline] [CrossRef]

12) Scholey M, Hair M: Back pain in physiotherapists involved in back care education. Ergonomics, 1989, 32: 179-190. [Medline] [CrossRef]

13) Poitras S, Blais R, Swaine B, et al.: Management of work-related low back pain: a population-based survey of physical therapists. Phys Ther, 2005, 85: 1168-1181. [Medline]

14) Campo M, Weiser S, Koenig KL, et al.: Work-related musculoskeletal disorders in physical therapists: a prospective cohort study with 1-year follow-up. Phys Ther, 2008, 88: 608-619. [Medline] [CrossRef]

15) Harutunian K, Gargallo-Albiol J, Figueiredo R, et al.: Ergonomics and musculoskeletal pain among postgraduate students and faculty members of the School of Dentistry of the University of Barcelona (Spain). A crosssectional study. Med Oral Patol Oral Cir Bucal, 2011, 16: e425-e429. [Medline] [CrossRef]

16) Shehab D, Al-Jarallah K, Moussa MA, et al.: Prevalence of low back pain among physical therapists in Kuwait. Medical principles and practice: international journal of the Kuwait University. Health Sci Cent, 2003, 12: 224-230.

17) Bork BE, Cook TM, Rosecrance JC, et al.: Work-related musculoskeletal disorders among physical therapists. Phys Ther, 1996, 76: 827-835. [Medline]

18) Miller AE, MacDougall JD, Tarnopolsky MA, et al.: Gender differences 
in strength and muscle fiber characteristics. Eur J Appl Physiol Occup Physiol, 1993, 66: 254-262. [Medline] [CrossRef]

19) Lalumandier JA, McPhee SD, Parrott CB, et al.: Musculoskeletal pain: prevalence, prevention, and differences among dental office personnel Gen Dent, 2001, 49: 160-166. [Medline]

20) Noh H, Roh H: Approach of industrial physical therapy to assessment of the musculoskeletal system and ergonomic risk factors of the dental hygienist. J Phys Ther Sci, 2013, 25: 821-826. [Medline] [CrossRef]

21) Cromie JE, Robertson VJ, Best MO: Work-related musculoskeletal disorders in physical therapists: prevalence, severity, risks, and responses. Phys Ther, 2000, 80: 336-351. [Medline]

22) Rempel DM, Krause N, Goldberg R, et al.: A randomised controlled tria evaluating the effects of two workstation interventions on upper body pain and incident musculoskeletal disorders among computer operators. Occup
Environ Med, 2006, 63: 300-306. [Medline] [CrossRef]

23) Carter JB, Banister EW: Musculoskeletal problems in VDT work: a review. Ergonomics, 1994, 37: 1623-1648. [Medline] [CrossRef]

24) Retsas A, Pinikahana J: Manual handling activities and injuries among nurses: an Australian hospital study. J Adv Nurs, 2000, 31: 875-883. [Medline] [CrossRef]

25) Retsas A, Pinikahana J: Manual handling practices and injuries among ICU nurses. Aust J Adv Nurs, 1999, 17: 37-42. [Medline]

26) Kai S: Consideration of low back pain in health and welfare workers. J Phys Ther Sci, 2001, 13: 149-152. [CrossRef]

27) Roh H, Lee D, Kim Y: Prevalence of work-related musculoskeletal symptoms and their associations with job stress in female caregivers living in South Korea. J Phys Ther Sci, 2014, 26: 665-669. [Medline] [CrossRef] 